\title{
Libertad republicana y sociedad civil. Apuntes para un debate
}

\section{Republican Liberty and Civil Society. A rejoinder}

\author{
Eduardo MAURA ZORITA
}

Universidad Complutense de Madrid

Recibido: 01/07/2010

Aceptado: 16/09/2010

\section{Resumen}

En este artículo se trata de evaluar críticamente las tesis fundamentales del libro de Carlos Fernández Liria y Luis Alegre Zahonero, El orden de El Capital (2010), en tanto que potencial lectura republicana de Marx.

Palabras clave: Libertad, Sociedad civil, Republicanismo, Subjetividad

\begin{abstract}
The purpose of this article is to discuss some arguments that Carlos Fernández Liria and Luis Alegre Zahonero use in their book The Order of Capital (2010) as means to an alleged "republican interpretation" of Marx.
\end{abstract}

Keywords: Liberty, Civil Society, Republicanism, Subjectivity

Desde la publicación de El orden de El Capital, Carlos Fernández Liria y Luis Alegre Zahonero se han visto involucrados en un tenso debate sobre el carácter mar- 
xista o no de sus tesis ${ }^{1}$. Mi intención es evaluar críticamente otra rama de su argumentación que la asimila a una posible lectura republicana de Marx.

Resumo brevemente las ideas principales del libro para ayudar al lector no familiarizado: los autores sostienen que (1) la ideología liberal ha hecho grandes esfuerzos por vincular las formas estado de derecho (en el sentido liberal de estado de derecho, a saber, la protección de las fronteras y la propiedad), capitalismo y libertad. Por su parte (2) la tradición marxista [que aquí incluye, con la debidas reservas histórico-políticas, a los partidos comunistas 2 y, más específicamente, a la marxología entendida como cuerpo hermenéutico de la obra de Marx y Engels] no habría visto tampoco con buenos ojos las figuras del estado de derecho, la libertad civil y el imperio de la ley. Este hecho es considerado por los autores un error fatídico, si bien es cierto que motivos históricos de peso ayudan a comprender esta decisión teórica y práctica. La «unidad indisoluble de derecho y capitalismo» y la idea de que el concepto de derecho «tal como es codificado por los autores de la Ilustración, no sería más que la codificación del individualismo burgués, y por lo tanto, tendría que ser superado por la ideología burguesa» (p. 21) son los referentes polémicos generales del libro. Se parte, por tanto, de que la indisolubilidad de capitalismo y libertad, capitalismo y derecho, es un artefacto ideológico del liberalismo [más concretamente del neoliberalismo de raigambre friedmaniana]. Todo ello para sostener que el capitalismo es incompatible con la imagen jurídico-política que proyecta: libertad económica, libertad política, capitalismo y estado de derecho serían no ya las caras de una misma moneda sino figuras antagónicas.

Aunque otros los han hecho profusamente ${ }^{3}$, no tengo voluntad de intervenir en semejante debate. Mi intención es considerar críticamente las categorías que el libro hace operar y que, siempre según sus autores, convertirían la suya en una lectura republicana de Marx. Para ello, me veo teóricamente obligado a neutralizar la variable marxológica, esto es, a no considerar el debate sobre lo que Marx quiso o no quiso decir en El Capital u otros textos relevantes. Puesto de otra manera: no es mi

\footnotetext{
1 Todas las citas de El orden de El Capital provienen de la edición publicada en 2010 en la editorial Akal y aparecen en el cuerpo del texto entre paréntesis. Las demás fuentes utilizadas siguen criterios de citación europea. Esta recensión se ha beneficiado de las discusiones con los autores y otras personas relevantes en el marco del Seminario de Investigación del Departamento Filosofía IV de la Universidad Complutense de Madrid. Agradezco por ello a todos los asistentes, entre los cuales se incluyen los propios Carlos Fernández Liria y Luis Alegre Zahonero, sus aportaciones. Este trabajo ha contado con una ayuda del programa de Formación de Investigadores del Gobierno Vasco.

2 Con reservas histórico-políticas, digo, porque existen potentes contraejemplos: Rosa Luxemburgo, Karl Liebknecht, el Franz Neumann laboralista pero no menos el Neumann autor de Behemoth. Estructura y acción en el nacionalsocialismo (1942, segunda edición ampliada de 1944), los derechos asociados a la vida social tal como aparecen en la constitución de Weimar de 1919 (que por cierto bebe directamente de fuentes jurídicas socialistas republicanas), etc.

3 Véanse a este respecto las contribuciones de Juan Pedro García del Campo en la revista digital Rebelión (www.rebelion.org).
} 
intención negar que en Marx pueda encontrarse un desarrollo categorial que permita cifrar una negación de esta aparente identificación entre capitalismo y libertad [algo que los autores llaman un procedimiento deductivo no dialéctico (dado que, aparentemente, lo que ellos llaman deducción dialéctica no comparece en El Capital)].

Aceptaré con ellos, como hipótesis de lectura, algunas tesis que podrían ser susceptibles de reformulación o matiz, renunciando asimismo a discutirlas. Por ejemplo, que es imposible deducir los conceptos fuerza de trabajo, plusvalor, tasa de ganancia, etcétera, de la idea de mercado o, mejor, de la forma mercado como espacio vacío apto para las relaciones jurídicamente libres e iguales entre productores o agentes económicos que poseen mercancías y los medios necesarios para producirlas. Aceptaré también -de cara a comprender la defensa por los autores de la teoría del valor como pauta de lectura de la totalidad social y no como regla de cada intercambio singular de mercancías- que, en función de la composición orgánica del capital asociada a la división social del trabajo y el intercambio, se modifica el sentido de la productividad de cada sector. Aceptaré, en consecuencia, que desde una aproximación singular a la teoría del valor se vuelve prácticamente imposible hacerse cargo de la totalidad social, con todos sus sectores productivos. También me parece un punto de partida razonable el hincapié que Carlos Fernández Liria y Luis Alegre hacen en la necesidad precisar mucho y bien qué se entiende por trabajo socialmente necesario (rendimiento del capital variable) para poder distinguirlo del rendimiento del capital constante. Históricamente, algunos lectores de Marx han olvidado estas cuestiones o no las han puesto suficientemente de manifiesto. Es por tanto una virtud del libro hacerse cargo de ellas.

La tesis de sus autores es relativamente clara: dado que el par decisivo no es capital/trabajo sino capital constante/capital variable, no puede decirse que sea lo mismo trabajar que funcionar (p. 566), pese a que ambos funcionen en el marco del capitalismo como parte del sistema del valor, esto es, como capital. Si Marx ha implementado la teoría del valor para dar cuenta de la relación social fundamental en las sociedades modernas -y sólo en ellas- ha sido porque ha querido determinar ésta no como «la que enfrenta a todos los individuos unos con otros como poseedores por igual de mercancías, sino la que enfrente, como clases, a trabajadores y capitalistas» (p. 566). Al igual que existen dos modos de productividad distintos (capital constante y variable, aquí sí, productividad del trabajo y productividad del capital), existen dos sistemas relacionales distintos que posibilitan de facto el funcionamiento correcto y ordenado del mercado: son el sistema del valor y el sistema de precios, que aquí serían relativamente independientes: «que dos inversiones iguales (en magnitud y tiempo de rotación) produzcan conjuntos de valores de uso distintos pero, en conjunto, del mismo precio, está muy lejos de significar que las cantidades de trabajo (en cualquier sentido posible de la palabra "trabajo") empleadas 
por ambas industrias hayan sido las mismas» (p. 569). Defender directamente la teoría del valor (esto es, que la magnitud de valor de una mercancía se decide en el tiempo de trabajo socialmente necesario para producirla) obliga a pagar un precio: la indistinción entre productividad del trabajo y productividad del capital. Y de ahí, el error de creer que es el mercado el que determina el tiempo de trabajo que se ha trabajado realmente, lo cual es relativamente inestable, dado que al mercado llega el producto del trabajo -la mercancía- y no la cápsula de trabajo X que satisface la necesidad Z. El mercado realiza precios individuales que son apropiadamente socializados para un género determinado de mercancías (léanse teléfonos móviles, coches u hogazas de pan). Valor y precio de producción son para los autores, con razón, magnitudes diferentes; ante todo, son cosas sociales diferentes. El valor depende del trabajo invertido, del trabajo vivo; el precio de producción, del capital invertido, con indistinción de si se invirtió en salarios -capital variable- o maquinaria y materias primas - capital constante. El negocio teórico de El Capital sería determinar con precisión estas diferencias; esto es, poner en su sitio teórico lo que el sentido común librecambista ha reunido abstractamente o, en otras palabras, ganar para la economía política el derecho a la experiencia (p. 131) y no tanto ejecutar un artificio dialéctico que deshaga el hechizo de la economía vulgar. La economía política no puede permitirse, si se quiere a sí misma como ciencia y no como vulgar accesorio científico de la ideología liberal, dejar de distinguir entre trabajar e invertir, «por mucho que en la sociedad moderna el trabajo sólo se pueda poner en juego como determinada cantidad de capital invertido» (p. 584).

El capitalismo es por tanto el lugar donde se pone en juego el intercambio de fuerzas productivas desiguales (capitalistas vs. trabajadores, unidos y separados por la forma mercancía y la forma capital), intercambio que redunda en profundas desigualdades sociales producidas por él mismo, desigualdades que reproducen el sistema social y lo hacen más agudamente inhumano. Es por esto que los autores consideran disparatado que Marx no confiara parte de su negocio práctico (en el sentido de su proyecto ético-político) a la defensa de una de esas clases, la clase formada, según el proyecto político de la Ilustración, por grandes agregados de sujetos de derecho, por cuerpos trabajadores de toda clase y condición que en la vida social portan derechos, deberes y dignidades. La distinción entre trabajar e invertir funciona también para diferenciar un mercado ideal de productos del trabajo de otro mercado de productos del capital. Esto es, que la clave de todo es la cuestión de quién posee los medios de producción, si el cuerpo de trabajo o el capitalista, y no tanto de si los productos de ese mismo trabajo se intercambian en el mercado o no. Hay mercados capitalistas y mercados no capitalistas [mercados en los que se intercambian mercancías que son de propiedad de quien las ha producido y cuyos medios de producción poseen en una medida u otra] lo cual remite, de alguna manera, a la idea jeffersoniana de una democracia de propietarios no capitalistas y, por 
extensión, a la juridificación de la acumulación de propiedad privada: habría, al menos tendencialmente, propietarios no capitalistas y propietarios capitalistas. $L a$ propiedad no es el problema, sino el capital. El mercado no sería por tanto la capital mundial del mal. Más bien, esta función social correspondería al capital, el cual por definición -dicho sea de paso, ya que los autores no lo mencionan- ha cancelado su localidad, su carácter espacialmente cifrable -al menos en tanto que capital financiero- con lo que la capital se ha vuelto mundo, el centro periferia, y así sucesivamente hasta la abolición de la «forma espacio» tal como la conocíamos.

El origen histórico del capitalismo, que Carlos Fernández Liria y Luis Alegre Zahonero releen como origen teórico, es la aniquilación de la propiedad fundada en el trabajo propio: la acumulación originaria o, si se quiere, la peculiar «posición original» del modo de producción capitalista, fundada en la desposesión de la propiedad del pequeño productor y los medios de producción hasta entonces a su disposición. Con ello ganan para el marxismo a la tradición republicana que, en efecto, ha considerado siempre la propiedad como un elemento decisivo para la independencia civil y la libertad política. Dicho kantianamente, «no agradecer la propia existencia al arbitrio de otro». Y tienen razón en este extremo: el Kant republicano ha visto claramente que la propiedad es una categoría de la relación, esto es, que la propiedad tiene que ser de algo exterior al cuerpo potencialmente propietario o, dicho con otras palabras, que uno no posee su pellejo, sino que es su pellejo, entre otras muchas cosas. La propiedad habrá de ser propiedad de algo: de un bien, de una mercancía, de los medios para producir alguna mercancía. La idea de que somos propietarios de algo cuando en realidad sólo nos poseemos a nosotros mismos es ajena a la tradición republicana, y con todo impera en el sentido común de generaciones de republicanos y no republicanos.

Hecho el resumen general y para comenzar, considero que la argumentación desarrollada a lo largo del libro ofrece al menos dos tipos de problemas:

(1) Metodológicos, que presentaré muy generalmente y en el sentido restringido del orden de las categorías que se ponen en juego.

(2) Sustantivos, relativos a las nociones sujeto de derecho, sociedad civil y libertad tal como operan en el libro de Carlos Fernández Liria y Luis Alegre.

\section{Metodología de las ideas (republicanas y no-republicanas)}

1.1. La primera cuestión se refiere a la metodología de las ideas políticas que aparecen en el libro de Alegre y Liria. Pudiera parecer que su intención era recuperar la conexión entre la teoría política y la economía política clásicas, esto es, entre el campo normativo y el campo institucional y, por extensión, el ámbito del diseño 
institucional ${ }^{4}$. Resultan a este respecto muy llamativas algunas ausencias: la más importante, una definición adecuada de estado de derecho ${ }^{5}$. Parece darse por supuesto que las condiciones de libertad civil, igualdad y propiedad serían sus pilares políticos, pero no queda claro si lo son como artificio polémico (para sostener la ruptura total del capitalismo con la imagen jurídico-política que proyecta de sí mismo) o de manera positiva (esto es, los autores las suscriben). Considero que ambas lecturas operan de igual a igual a lo largo del texto.

Como tales, dichas categorías podrían ser perfectamente republicanas, pero al precio de no distinguir positivamente, por poner tres ejemplos, entre las instituciones propias de una democracia de propietarios (no capitalistas) à la Thomas Jefferson, un estado asistencial de máximos (que hiciera a grandes agregados de población propietarios de sus funciones, a saber, funcionarios) o una sociedad civil intervenida bajo criterios sustantivos de equidistribución periódica de las rentas de capital y trabajo y atravesada por corporaciones democráticas (desde el colegio profesional a la pequeña empresa, pasando por iglesias o consejos vecinales). Versiones todas ellas de cierto ethos republicano, pero en la práctica incompatibles entre sí. Aquí el problema no me parece tanto de contenido (creo que la voluntad republicana de los autores está fuera de toda duda) como de metodología de las ideas. Si el libro adolece completamente de la segunda parte de la ecuación republicana es porque sus categorías básicas se mueven en el plano de las teorías ideales (en el mejor sentido del término, sin duda, pero ideales al fin y al cabo): el nivel de la exploración normativa de juicios y formas tales como estado de derecho o capitalismo que, siendo aparentemente compatibles, resultan no serlo teóricamente y, por tanto, pueden ser contestadas, defendidas o pensadas productivamente.

Las incontables ocasiones en las que Luis Alegre y Carlos Fernández Liria hablan de la imposibilidad de deducir del mercado la categoría plusvalor, entre otras, da fe de que su proyecto filosófico está decidido a reparar un error teóricopráctico, a saber, el clamoroso alejamiento de la marxología del proyecto ilustrado, distanciamiento al que los autores asocian tanto la insolubilidad del bizantino problema de la transformación de valores en precios, entre otras estrellas de la tradición marxista, como, en un nivel distinto, la deriva esquizopolítica del estalinismo realmente existente, incapaz, claro está, de pensar la persona, los derechos asociados al cuerpo y al trabajo o, peor todavía, la vida humana como intrínsecamente valiosa. Omiten, sin embargo, todo un ámbito de problemas que, siendo circunstanciales desde el punto de vista de su lectura de Marx [lo que se llamaría en filosofía

\footnotetext{
4 Me baso en buena medida en Bertomeu, M. J. y Domènech, A.: «El republicanismo y la crisis del rawlsismo metodológico (Nota sobre método y sustancia normativa en el debate republicano)», en Isegoría, $\mathrm{n}^{\circ} 33,2005$, p. 52 y siguientes.

${ }^{5}$ Se verá más adelante en qué sentido no hay tal definición, aunque, en todo caso, su ausencia llama poderosamente la atención.
} 
política las circunstancias de la justicia, o, en este caso, de la libertad y la propiedad], son consustanciales a la tradición republicana. Dicho muy groseramente, la tradición republicana se distingue por el acercamiento profundo que lleva a cabo de teoría política, economía política y economía moral, así como en no poder pensar la norma sin pensar su codificación positiva y las condiciones materiales de su efectividad. Luis Alegre y Carlos Fernández Liria no ejecutan este procedimiento republicano. Más bien, buscan encontrar en El Capital un acicate teórico, sin duda legítimo, para pensar formas de relación social que distingan correctamente unos mercados de otros, unos derechos de otros, unas formas de productividad de otras: poner todo en su sitio a partir del edificio crítico puesto por Marx. Con ello dan un paso interesante hacia una lectura republicanizante de Marx, pero no llevan a cabo una lectura propiamente republicana.

$\mathrm{Su}$ libro no puede ser una lectura republicana porque su propia estrategia es negativa: rescatar a Marx del marxismo puede valer como primer paso, pero proponer una teoría republicana del estado o de la sociedad civil es una tarea que exige otros términos y otros interlocutores. Para culminarla, por establecer una pauta concreta, haría falta una propuesta ético-política positiva e históricamente determinada, a saber, una definición practicable de estado de derecho que trascendiera sus fundamentos básicos e incluyera determinaciones positivas y pautas para el diseño de instituciones republicanas que pudieran portar y sostener históricamente las fuerzas de independencia, libertad y propiedad que sin duda Carlos Fernández Liria y Luis Alegre veneran honestamente. Entiendo que para ellos se trate de recuperar a cierto Marx, y que en ese sentido sea relevante para su proyecto llevar a cabo una lec-

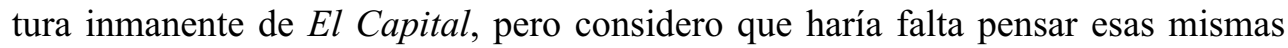
categorías en el marco de sus recientes trasformaciones para estar en disposición metodológica de abrir a Marx al republicanismo y, por ende, más allá del estrecho campo de la marxología.

1.2. En segundo lugar, la metodología de las ideas que los autores utilizan es tendencialmente a-histórica y poco ajustada al problema de fondo, si, como creo, éste es el de desarrollar una lectura republicana de Marx ${ }^{6}$. Queda por determinar en qué sentido una lectura republicana de Marx puede tomar pie en las sin duda interesantes posturas de L. Althusser y F. Martínez Marzoa a propósito del debate sobre el tránsito del feudalismo al sistema capitalista; un tema clásico, dicho sea de paso, de la marxología, pero ajeno al republicanismo metodológico. Efectivamente, me parece perfectamente aceptable sostener que «no hay manera de encontrar en $E l$ Capital una ley que explique el surgimiento de la sociedad capitalista a partir de la

\footnotetext{
6 A este respecto, es también (deliberadamente) anacrónica la imagen a la que los autores confían el espíritu del libro: «Marx como Galileo de la historia». No podía ser de otra manera, dado que sus fuentes y problemas son de otra índole material e histórica. Con todo, la forma Galileo aclara solventemente el enfoque general del libro.
} 
sociedad feudal, o su necesaria transformación en la sociedad comunista» (p. 130). Y puedo compartir que a partir de la voz hegeliana Aufhebung algunos han hecho y dicho barbaridades muy considerables, pero no precisamente relativas al proyecto marxiano sino más bien al de los partidos comunistas que, dicho sea de paso, a partir de la hegemonía de la III Internacional no necesitaron cambiar mucho para permanecer, ni negar tantas negaciones como pudiera parecer. En estos casos, el mero dominio suele bastar. En todo caso, no parece que las categorías de este debate sean históricamente relevantes para una lectura republicana de Marx.

Entiendo que se trata -por parte de los autores- no tanto de fomentar directamente un Marx republicano como de contestar a la tradición marxista-historicista y sus arteros negocios dialéctico-hegelianos. Pero en este sentido, sin desmerecer a Althusser o Marzoa, es la tradición del marxismo occidental -de Lukács al joven Habermas, tradición esta que permanece completamente ausente en el libro- la que ha hecho con Hegel cosas bastante más interesantes que la tradición estrictamente marxológica. Cosas nada arteras. No se halla entre las menos relevantes la determinación de que Hegel, con respecto a Kant, ha ganado un terreno importante: «si con Kant la crítica lo es de la razón, con Hegel, que critica a su vez el divorcio kantiano de la razón y la realidad, la crítica de aquella se vuelve, a la vez, de lo real: la insuficiencia de todas las determinaciones singulares aisladas es siempre, al mismo tiempo, insuficiencia también de la realidad particular aprehendida por tales determinaciones» ${ }^{7}$. Dicho de otra manera, para Hegel no se trata de pensar categorías más depuradas, sino de hallar la manera filosófica de liberar la fuerza del objeto («no hay hechos sino para teorías», suele decir Jacobo Muñoz glosando a Popper con acento dialéctico) y que éste pueda decirnos algo. Se trata de volver crítico-productiva la actividad de filosofar y, más precisamente, de pensar el presente en su totalidad, con todas las aporías y problemas insolubles que ello pueda acarrear.

Al rechazar una lectura con más mediaciones, los autores introducen una cesura entre la lectura de El Capital, la crítica de la tradición marxista y la filosofía política republicana que se mantiene a lo largo de todo el libro y que dificulta en buena medida su lectura: ¿hablamos de Marx o del marxismo? ¿De la tradición socialista republicana o del marxismo de los partidos comunistas? ¿De un Marx republicano o de una lectura republicana de Marx? ¿De El Capital o del capital realmente existente? ¿De un proyecto basado en el análisis de Marx del capitalismo, proyecto que, una vez derrotado éste, si tal cosa sucediera algún día, ganaría para la sociedad un proyecto republicano actualmente impotente? ¿En qué consiste una lectura republicana de Marx? Lo que Marx no ha construido, ¿está Kant en condiciones de ofrecerlo políticamente?

Asombra al lector, desde el punto de vista metodológico, que se dediquen tantas páginas a debates en los que operan categorías a-históricas, al menos en la for-

7 Adorno, Th. W.: Tres estudios sobre Hegel, Madrid, Taurus, 1974, p. 109. 
mulación que Luis Alegre y Carlos Fernández Liria toman como punto de partida: más allá de la siempre pertinente crítica al triunfalismo progresista socialdemócrata de finales del siglo XIX y principios del XX, me parece a estas alturas más que discutible decir que el método dialéctico, tal como comparece en Hegel, tuviera algo que ver con algún «misterio "frankfurtiano" sobre la relación entre teoría y praxis» o con la investidura de la «historia universal como tribunal supremo de la historia» (p. 147). Sin embargo, los autores parecen suponer que de hecho es o sigue siendo así. Pero no aclaran en qué sentido el obsoleto debate sobre la dialéctica hegeliana, como si ésta fuera una, clara y distinta [cosa que ningún Hegel-kenner de Goethe en adelante sostendría, no desde luego en el ámbito de la tradición marxista occidental, más concretamente, en la vertiente de Lukács y Adorno] afecta a la sustancia del debate republicano. Más bien, considero que el método dialéctico no se ajusta -ni espacial ni históricamente-al campo de la metodología de las ideas del republicanismo, sea a través de Marx o de cualesquiera otros autores relevantes a estos efectos ${ }^{8}$. La demolición de la dialéctica-si en El orden de El Capital se hubiera acometido esta tarea- no serviría a los propósitos de un Marx republicano, como tampoco parece que la apología del «método dialéctico» mistifique automáticamente el cuerpo de la obra de Marx, por ejemplo a través de su «desilustración». Sólo cabe tal resultado si uno ha diseñado la censura a-dialéctica de una dialéctica previamente mistificada, no menos impropia de Hegel que del Lukács de Historia y conciencia de clase (1923).

En esta línea, el uso de la categoría Ilustración es también altamente a-histórico: existe para los autores un lado malo de la Ilustración (¿de Hobbes a Hegel, qui-

\footnotetext{
${ }^{8}$ El caso es que la tradición hegeliana se mueve en coordenadas completamente diferentes desde hace muchas décadas, ajena a las voladuras dialécticas de este presunto «lado malo» de la tradición marxista. Aprovecho para aportar una buena definición de dialéctica presente en la introducción de Volker Rühle a la reciente edición en la Biblioteca de Grandes Pensadores de la editorial Gredos de algunas obras selectas de Hegel: «Forma del pensamiento no objetivo que se retrotrae a Platón, en el que designa un procedimiento para superar contradicciones en el pensamiento y en el ser. Esta superación no es una operación subjetiva que se oponga a la contradicción, sino que consiste en el conocimiento de su conexión interna. La dialéctica es entonces un pensar que, interiorizándola o recordándola, penetra en esta conexión de la contradicción y saca a la luz su génesis y su lógica interna. Entonces la apariencia de los polos opuestos cambia, y cambia también la perspectiva del pensamiento, que antes sólo había percibido esa conexión como contradicción. Por eso la dialéctica no es para Hegel un procedimiento operativo del que la filosofía se sirve en relación con los objetos, sino la lógica y el automovimiento autónomos de la cosa misma, es decir, de la entera conexión de una contradicción existente y de la forma de pensamiento que la presupone», en Hegel, vol. I, Madrid, Gredos, 2010, p. CV. Una de las grandes virtudes del pensamiento hegeliano es precisamente que la irrupción del pensamiento especulativo y su aspiración a conocer «toda la verdad» es que él mismo se concibe como una forma históricamente determinada, como un fenómeno histórico que comparte tiempo y espacio con otros fenómenos igualmente históricos. Es por ello que la filosofía de Hegel no reposa en ningún método dialéctico. De hecho, no toma pie definitivamente en ninguna formulación o configuración concreta de la experiencia.
} 
zás?) y un lado bueno (Locke y Kant), pero en ningún caso una problematización del desarrollo histórico del proyecto ilustrado. La Ilustración, por definición, no tiene tanto un estatuto bifronte, que también, como un estatuto de problema. Si algo caracteriza a la Ilustración ha sido, en buena medida, su propia autocomprensión problemática. Podemos ver esto en el tránsito de Rousseau a Kant; o en el propio Kant tratando de mostrarnos por qué el peluquero no puede votar y el fabricante de pelucas sí. Más explícitamente, Kant duda en el borrador de su trabajo sobre el tópico sobre como poner el francés fraternité: escoge Verbrüderung (fraternización) y escribe a su lado weltbürgerliche Einheit (unidad cosmopolita), pero al tratar de aclarar los términos de su confusa traducción, introduce un nuevo problema: fraternité se convierte finalmente en Selbständigkeit (autonomía) «en la que ésta se presupone sin contrato». En tanto que sólo los sui iuris (los hombres libres) pueden cerrar contratos, Kant está dando un paso adelante: autonomía sin contrato es una fórmula feliz desde un punto de vista republicano. Pero él mismo se resiste a dar el paso a la democracia plena, esto es, a elevar a aquéllos que no son sui iuris a la sociedad civil adjudicándoles «derecho de existencia»: resistencia, en suma, a iniciar un camino que no es otro que el de la redistribución de la propiedad a gran escala ${ }^{9}$. Y es que, más allá del capitalismo rampante, tampoco la «forma Ilustración» ha sido clara, triunfante y distinta, como bien ponen de manifiesto los avatares histórico-políticos de Napoleón, la Aufklärung berlinesa, Savigny o Haller.

Cabe leer estos procesos en la problematización de Hegel de una sociedad civil que no es ya comunidad natural o reproducción avanzada de un estado (socializado) de naturaleza, sino un orden de transparentes antagonismos sociales que deben ser regulados por un Estado -por cierto, de derecho. Hegel lo estudia materialmente en sus Principios de filosofía del derecho de 1820/1821, obra magna del Hegel berlinés que, intuyo de forma deliberada, permanece ausente a lo largo del libro de Carlos Fernández Liria y Luis Alegre: individuo y sujeto económico, libertad y propiedad, razón y carencia de universalidad efectiva del ordenamiento social, son allí para Hegel pares decisivos para la comprensión de las transformaciones de la sociedad civil en el periodo de la Ilustración; periodo, en última instancia, caracterizado por el auge de la forma consumada de la burguesía y por la socialización del principio de competencia (entre otras muchas cuestiones de suyo ilustradas, sobre todo de orden epistemológico y político).

\footnotetext{
${ }^{9}$ Cfr. Domènech, A.: El eclipse de la fraternidad, Barcelona, Crítica, 2004. También, mi contribución al Congreso «Respuesta a la pregunta: ¿Qué es Ilustración? (1784-2010)», titulada «¿De qué hablamos cuando hablamos de Ilustración hoy?», de próxima publicación en actas, y en el que también participaron Carlos Fernández Liria y Luis Alegre Zahonero.
} 


\section{Problemas sustantivos}

2.1. Como consecuencia indirecta del tratamiento de las categorías de El orden de El Capital, quedan pendientes de definición algunas categorías y formas importantes: por ejemplo, el sujeto de derecho, que solamente definido en términos de aquellos principios normativos que tendrían que imperar en el orden social republicano resultante: libertad civil, igualdad y propiedad ${ }^{10}$. Cabe pensar que en este punto los autores sí son de hecho bastante heideggerianos (véase el prólogo de Santiago Alba Rico, pp. 13-14): su sujeto de derecho adquiere una tonalidad ambigua impropia de un ciudadano ilustrado que debiera ser sustraído a las presiones del mercado, como si de hecho las modernas sociedades capitalistas se cernieran sobre él y, para conquistar y mantener su independencia civil, tuviera que enfrentarse a ellas como quien se opone a un peligro cósmico, a la manera de la técnica en Heidegger.

Tomando pie en una distinción clásica, más que un hombre que puede y debe ejercer como ciudadano, este sujeto parece un mero hombre: un Mensch que existe actualmente más allá de sus espacios de civilidad, a los que aparentemente accede -o no- en función (1) de estados exteriores [bien legales, tales como las normas de participación en los asuntos de la comunidad, bien personales, a saber, sus inclinaciones o condiciones materiales particulares de existencia], más allá (2) de su biografía socioeconómica [que los autores, dicho sea de paso, sólo piensan sociológicamente en términos de clase trabajadora, sin mayor precisión o determinación de las transformaciones que tal concepto ha sufrido en los últimos cincuenta años y que, además, no viene acompañada de referencia alguna a la historia y práctica del movimiento obrero] y (3) de su red de prácticas sociales. Las determinaciones del sujeto de derecho tal como se exponen en El orden de El Capital no vienen dadas por las formas de subjetividad asociadas a la producción de norma, ni sus derechos toman cuerpo en las instituciones de una sociedad civil aquí francamente despoblada [apenas hay referencias a la sociedad civil, más allá de algunas referencias que la asimilan a las sociedades «en general»]. Luego cabe pensar que la lectura de Luis Alegre y Carlos Fernández Liria contiene, sin pretenderlo y a la manera heideggeriana, elementos de una protesta bien fundada sobre criterios marxianos (pero mera Klage al fin y al cabo) en nombre del hombre mismo (Mensch) contra la civilización occidental capitalista y sus efectos deshumanizadores (Enthumanisierung). Y que, en consecuencia, no se trata, al menos en este estadio, de un proyecto político republicano que presuponga que el diseño institucional es sustantivamente relevante porque el sujeto de derecho se construye precisamente en las instituciones democráticas, sus prácticas y reglas asociadas: un sujeto que toma cuerpo en ellas, fun-

10 Asumo aquí, provisionalmente, que se trata de uno de los momentos en los que los autores defienden activamente los principios de libertad civil, igualdad y propiedad. 
ciona y trabaja en ellas, un sujeto que sólo ejerce su libertad individual en el marco positivo de una vida social libre y que como tal concibe la libertad, a saber, como expresión activa y humanamente digna de una forma social bien ordenada [respetando, naturalmente, las diferentes versiones del tipo de sociedad deseable y la imprescindible consideración de las condiciones socioeconómicas dadas para su construcción]. Dicho todo esto a sabiendas de que no todas las tradiciones republicanas piensan la vida social de esta guisa: no es lo mismo la democracia (de propietarios) no capitalista de Thomas Jefferson que la Comuna de París, como no equivalen tampoco las conquistas del movimiento obrero alemán de principios del siglo pasado al republicanismo de Jiménez de Asúa. En todo caso, y con las debidas precauciones, la tradición republicana socialista -a la que creo se adscribirían idealmente Carlos Fernández Liria y Luis Alegre- sí defiende una economía civil como la que he descrito.

En resumen, el sujeto de derecho que los autores proponen es de hecho del género fantasmagórico: sabemos que sus determinaciones morales, sociales y económicas deben ser protegidas de la lógica del mercado, pero no sabemos nada más sobre él. Las categorías de la propuesta política republicana de los autores operan sobre este sujeto como si sobre él se cerniera una amenaza precisa y profusamente comentada (el capitalismo) pero cuyas víctimas potenciales [¿como hombres o como ciudadanos? Ambos a la vez, cabría pensar] son sencillamente ininteligibles por sí mismas, o lo que es más grave, a través de las instituciones en las que operan. Creo que el problema de fondo es doble: (1) la forma sujeto es concebida a-históricamente, dando pie a lo que Adorno tematizara como «absoluto dualismo entre el proceso de cosificación y la interioridad pura» ${ }^{11}$. Este dualismo tiene consecuencias decisivas para la codificación positiva de un proyecto republicano, dado que parte de una lectura de los modernos procesos de subjetivación completamente ajena a esa tradición: el hombre ostenta aquí una «imagen estática» y su determinación deviene «la más vacía y pobre de todas» ${ }^{12}$. La apelación a los derechos de la experiencia por parte de Luis Alegre y Carlos Fernández Liria llama tanto más la atención en cuanto, proviniendo de una crítica del método dialéctico y de la adopción del procedimiento kantiano en el ensayo «Sobre el tópico» o El conflicto de las facultades [a saber, la idea de que la razón no habrá de ceder en su capacidad configuradora de realidades más justas, cabe decir republicanas, de acuerdo con principios de racionalidad, libertad e igualdad], no configura sin embargo la forma sujeto de derecho que, en última instancia, trataría de salvar (y no sólo para la experiencia). (2) Los autores parecen querer vaciar la forma sujeto de derecho para demostrar que el capitalismo actualmente existente no se corresponde en absoluto con la

11 Adorno, Th. W.: «Individuo y organización», en Obra completa, 8. Escritos sociológicos I, Madrid, Akal, 2004, p. 418.

12 Adorno, Th. W.: «Individuo y organización», op. cit., p. 419. 
imagen que proyecta de sí mismo, esto es, una en la que la libertad económica [más específicamente, la libertad de movimiento de capitales y su reverso tenebroso, el endurecimiento progresivo de las leyes que rigen la movilidad de la fuerza de trabajo] comporta necesariamente libertades políticas o de hecho, las presupone. De esta manera obtienen una forma vacía bipartita: estado de derecho y sujeto de derecho, formas que ni siquiera entendidas en abstracto servirían automáticamente al capital. Deben ser forzadas, violentadas incluso, para convertirse en tales servidoras. Y como tales formas vacías, podrían ser completadas con una concepción del bien [el comunismo, según se dice en la p. 634, y que por definición posee una concepción muy precisa del bien, a saber, la justicia propia de grandes grupos de hombres socializados que conforman una comunidad de productores libres e iguales].

Desde un punto de vista filosófico-político, esta estrategia ostenta una doblez muy significativa: por un lado se defiende el potencial emancipatorio de la forma derecho «en sí», pero no se determina en ningún caso la orientación de la acción legislativa y reglamentaria que, de facto, habría de ser social y necesariamente efectiva si el proyecto político que Luis Alegre y Carlos Fernández Liria defienden quisiera tener un mínimo de posibilidades de imperar y, ante todo, subsistir a medio plazo. Se trata de no ya de dos líneas de trabajo o momentos teóricos analíticamente separables, sino de dos niveles distintos de argumentación que reproducen netamente la dicotomía ética/política: la norma vacía operaría contra el capitalismo y la imagen de sí mismo que ofrece; la norma, una vez llena -cabe decir republicaniza$d a-$, trabajaría por el socialismo. Las consecuencias inmediatas de este argumentario me parecen evidentes: el estado de derecho pasa a ser definido negativamente como esfera de protección del ciudadano-hombre, como «otro mundo en el mundo» (Hölderlin) y no, republicanamente, como (1) conjunto de prácticas institucionales de recuperación activa de un sistema de distancias jurídico-políticas entre capital y trabajo; y (2) como codificación positiva del orden de los derechos y de las condiciones materiales de su efectividad; en resumen, la producción de espacio social y tejido público. Y es que, en definitiva, «la tradición republicana no pone en el centro de su atención normativa la justicia distributiva, sino que la justa distribución del producto social sería un resultado derivado de su atención principal a los problemas de extensión social (mayor o menos) de la libertad republicana a individuos socialmente regimentados, es decir, institucionalmente repartidos, de uno u otro modo, entre las distintas clases sociales que componen una sociedad civil» 13 .

Los autores reproducen de alguna manera el moderno dilema entre libertad y necesidad, esencia y apariencia: entendidas capitalistamente como fatales legaliformidades, las leyes naturales-sociales del capital no pueden ser penetradas directamente por la libertad, ni dotar a estas leyes naturales fatalistas de sentido: «los contenidos suministrados [a su vez, EMZ] por la razón que conoce, el mundo por ella

13 Bertomeu, M. J. y Domènech, A.: op. cit., p. 66. 
conocido, son igualmente incapaces de llenar de vida viva las determinaciones formales de la libertad» 14 . Esto se debe, en mi opinión, a que los autores no piensan el estado de derecho republicanamente: conservan y fomentan el hiato forma/contenido del derecho que el republicanismo trata de salvar metodológicamente. La contrapartida filosófica de esta cuestión la hallamos, me parece, en su negación del potencial crítico de toda modalidad posible del procedimiento dialéctico: en consecuencia, el estado de derecho, que personificaría estructuralmente la condición de la libertad, se presenta bajo la forma pasiva de la libertad vacía que trata de sustraerse «al abismo del fatalismo» del capital. Al irracional contenido social del capitalismo se opone la racionalidad de la forma derecho, pero no con la mediación de alguna conexión concreta entre forma y contenido [por ejemplo, la buena norma republicana] sino como «material de un cálculo puramente formal» 15 .

A su vez, esta estructura se corresponde -coherentemente- con una concepción del capitalismo que posee cierto parecido de familia con la rama heideggeriana de la revolución conservadora (y en este sentido, parcialmente compatible con la distinción habermasiana entre mundo de la vida y sistema ${ }^{16}$ ); una imagen del capitalismo por la cual, digámoslo provocativamente, bombas de racionalidad cosificadora aspirarían a colonizar el espacio vital del hombre (y del potencial sujeto de derecho) a través de la lógica mercantil: dinero y poder. Según este guión, mientras el quebradizo sujeto moderno - genuino representante de las fuerzas vivas de la humanidad- pelea por su existencia, el napalm financiero especulativo trata de insertarse en sus formas de vida, de transformar su sentido común para que, de esta manera, tras la victoria final, el sistema colonizador proceda a resignificar los términos y permita de esta guisa -teórica y práctica- la emergencia de la libertad: así, llegamos

${ }^{14}$ Lukács, G.: Historia y consciencia de clase, vol. II, traducción de M. Sacristán, Barcelona, Orbis, 1985 , p. 69.

${ }^{15}$ Lukács, G.: op. cit., pp. 68-69. Cfr. «Rosa Luxemburg como marxista», en G. Lukács, Historia y consciencia de clase, vol. I, Barcelona, Orbis, 1985, p. 99. Allí Lukács califica esta clase de operación filosófica como "oposición ética» al capitalismo, asignando precisamente a Rosa Luxemburg una posición crítica sustantiva, si bien no exenta de debilidades. Se trata del problema de la fundamentación meramente ética de la crítica al capitalismo, que según Lukács procede de la omisión del punto de vista metodológico de la totalidad social. Esta posición, asociada al postulado del deber-ser y la ética de los imperativos (sólo) subjetivamente eficaces, ofrece como alternativa emancipatoria la huida del sujeto hacia el abismo de la subjetividad libre, posición desde la cual las leyes sociales del capitalismo se presentarían como terribles y absurdas, ajenas a la acción social del hombre, en suma, cosificadas; más terribles, si cabe, en la medida en que este sujeto no encuentra otro sustrato material que este producto suyo aparentemente independiente y, visto el panorama, se siente incapaz de disputarlas. En otras palabras: el dilema de la impotencia. Por mi parte, creo que Lukács no lleva toda la razón. Sin embargo, es cierto que la estricta dicotomía forma /contenido (del derecho y la libertad) conlleva este riesgo; uno que el republicanismo metodológico se ha esforzado históricamente por evitar.

16 Cfr. V. Gómez, «Mundo administrado o colonización del mundo de la vida. La depotenciación de la Teoría Crítica de la sociedad en J. Habermas», en Daimon. Revista de Filosofia, nº 10, 1995, pp. 103-113. 
de nuevo al problema de la indeseable indisoluble unidad de derecho y capitalismo, capitalismo y libertad.

Comparto con los autores la relevancia práctica de la distinción entre estado de derecho y capitalismo, pero no puedo estar de acuerdo con un diseño teórico que piense el capitalismo como fuerza colonizadora a la que debemos sustraernos si queremos construir o conservar un mundo de la vida ordenado y justo, y no como civilización de pleno derecho, como sistema $y$ mundo de la vida. Ambas visiones, me consta, no son incompatibles, pero sí perfectamente distinguibles: en El orden de El Capital opera una cierta indistinción entre ambas que afecta poderosamente a la esfera de la sociedad civil, a la que me referiré a continuación.

2.2. En esta línea, la forma sociedad civil se presenta igualmente desdibujada, cosa harto llamativa tratándose de una lectura republicana de Marx. Por ejemplo, cuando los autores discuten un tema importante como es la distinción entre competencia capitalista y principio de competencia entre iguales, afirman que «la competencia capitalista, sencillamente, es una cosa distinta a la competencia que enfrentaría entre sí a los individuos como miembros de la sociedad civil» (pp. 611-612). Y más adelante, a propósito de esta misma cuestión, vemos como «terminó resultando innegable que si se ignoraba esa distancia que separa al mercado capitalista de la mera libre competencia entre miembros cualquiera de la sociedad civil, entonces se generaban de modo inevitable unas condiciones sociales para la mayoría de la población sencillamente incompatibles con el ejercicio de ningún derecho civil o político» (p. 614). Me parece que la determinación de la sociedad civil, que no es definida en ningún momento del libro, así como la identificación de derecho civil y espacio civil, exige una doble aclaración.

(a) Para la tradición liberal, ampliamente entendida, el Estado emerge de la sociedad civil como su garante y marco facilitador, y ésta se define precisamente por ser «una esfera establecida para que en ella se realizaran los intereses individuales en un marco competitivo, contractual, que permitiera la privacidad y la intimidad, como había puesto de relieve con vigor Benjamin Constant, y no sólo el disfrute de los derechos y la propiedad privados» 17 . Parecería que los autores de $E l$ orden de El Capital piensan también en estos términos al establecer la determinación de que la competencia capitalista se distingue perfectamente de la competencia civil. Sin embargo, existe en la historia de la filosofía práctica una poderosa línea de interpretación no contractualista y enormemente crítica de la sociedad civil liberal. Me refiero, es obvio, a G. W. F. Hegel.

17 Giner, S.: «Sociedad civil», en E. Díaz y A. Ruiz Miguel (eds.), Filosofía Política, II. Teoría del Estado, Madrid, Trotta, 1996, p. 121. Se trata del volumen décimo de la Enciclopedia Iberoamericana de Filosofía (EIAF). 
Hegel mide con precisión la conveniencia -o no- de proponer un modelo jurídico-político que no se haga cargo, corrigiéndolas, de las determinaciones de la sociedad civil realmente existente: ese «campo de batalla [Kampfplatz] del interés privado individual de todos contra todos» 18 en el que la libertad positiva no puede tomar cuerpo. El liberalismo propone «el principio de los átomos, de las voluntades individuales: todo debe ser obra de su poder expreso y de su expresa aprobación» 19 . Se trata, en última instancia, de la reducción del estado a la sociedad civil, pero no a una sociedad civil cualquiera: en tiempos de Hegel, se trataba de una sociedad civil profundamente atravesada por el principio crecientemente capitalista de competencia civil. En nuestros días, la sociedad civil se halla sometida a imperativos muy contundentes de socialización: «se trataría de la rápida reconversión del orden social dominante en un orden de flujos y redes que se asienta en una creciente movilidad [...] de capitales e inversores, y sobre una explícita política de precariedad que permite flexibilizar las relaciones laborales y sociales en dos sentidos: (1) deslocalización y (2) debilitación de los signos de pertenencia a la organización. Este orden se encuentra en un estado de crisis evidente, pese a que tiene cierto carácter de novedad epocal» 20 . Por decirlo hegelianamente, en la sociedad civil, incluso allí donde no opera el capitalismo en su forma consumada, se dan modos formales de libertad [derecho abstracto en Hegel, esto es, derecho civil de mínimos: la forma propiedad y la posibilidad de firmar contratos, ambas indisolublemente unidas a las diferentes fases de la división social y técnica del trabajo] que dificultan sobremanera la consolidación de instituciones democráticas del calibre que el proyecto de Carlos Fernández y Luis Alegre requiere. Me parece que, en este sentido, Hegel opone al cuadro liberal una objeción muy importante: en la sociedad civil no rige el principio de todos contra todos, ni se trata de un nuevo estado de naturaleza. De hecho, no es tampoco un orden el que impera la mera irracionalidad. Es el caso, más bien, de que las formas de racionalidad imperantes son solamente formales porque

\footnotetext{
18 Hegel, G. W. F.: Principios de la filosofía del derecho, traducción de Juan Luis Vermal, Barcelona, Edhasa, 1988, § 289, p. 438, citado en P. López Álvarez, «Estado de derecho y principio democrático», ponencia leída en el Congreso Internacional Hegel: la experiencia de la libertad. 200 años de la Fenomenología del espíritu, celebrado los días 3, 4 y 5 de diciembre de 2007 en la Facultad de Filosofía de la Universidad Complutense de Madrid. Sigo a P. López en este punto.

19 Hegel, G. W. F.: Lecciones de filosofia de la historia universal, traducción de José Gaos, Madrid, Alianza, 1980, p. 697: «Nicht zufrieden, daß vernünftige Rechte, Freiheit der Person und des Eigentums gelten, daß eine Organisation des Staates und in ihr Kreise des bürgerlichen Lebens sind, welche selbst Geschäfte auszuführen haben, daß die Verständigen Einfluß haben im Volke und Zutrauen in demselben herrscht, setzt der Liberalismus allem diesen das Prinzip der Atome, der Einzelwillen entgegen: alles soll durch ihre ausdrückliche Macht und ausdrückliche Einwilligung geschehen». Citado en P. López, op. cit.

20 Maura Zorita, E.: «Trabajo, industria cultural y transformación del sentido común. Notas para un diálogo con Jacobo Muñoz», en J. Muñoz (ed.), Melancolía y verdad. Una introducción a la lectura de Th. W. Adorno, Madrid, Biblioteca Nueva, 2011 (en prensa).
} 
toman pie en la distinción entre burgués y ciudadano, que a su vez «fija los límites de un punto de vista que reduce al individuo al estatuto de persona jurídica (sujeto del derecho privado) y actor económico. [...] El burgués -no como individuo sino como figura ética- es quien, condenado por su relación con el trabajo y con el beneficio a "hundirse en la posesión y la particularidad", "no es capaz ni de virtud ni de bravura" $\gg 21$. Hegel se hace cargo aquí de una ambigüedad sustancial para el problema de la sociedad civil: los individuos no se enfrentan como tales en la sociedad civil salvo que los consideremos sin ninguna determinación socioeconómica, y es sobre esta ambigüedad sobre la que se funda la afirmación por la cual competencia civil y competencia capitalista no son iguales. Ciertamente es así, pero es que para que se pueda dar una sana competencia civil entre productores libre se iguales no basta con disputar al capitalismo el monopolio del principio de competencia. Hegel sabe bien que la sociedad civil no caminaría por sí misma hacia ese estadio social, dadas las condiciones entonces existentes, porque es precisamente la despolitización de las formas de socialización la que ha engendrado semejante sistema de necesidades. El sistema de las necesidades es de suyo un modo de socialización, y como tal parece que resistiría sin problemas la retirada del capitalismo en cualesquiera modalidades o que, al menos, no avanzaría hacia un modelo de competencia civil libre e igualitario.

¿Por qué? Por el propio desarrollo de la división social y técnica del trabajo que el auge de la burguesía como agente económico fundamental y la emancipación de las formas feudales comporta. Esto es, no es tan fácil diferenciar hoy entre capitalismo y sociedad civil, dado que la sociedad civil ha sido, de hecho, tal como la conocemos hoy, un espacio de interacción privada enormemente ligado al surgimiento de la modernidad capitalista, muy particularmente a su prosecución de autonomía socioeconómica. Que el proyecto ilustrado, como atestigua la posición crítica de Hegel, no comparta totalmente este modelo, o incluso que defienda otro, no significa que de hecho la competencia civil sea fácilmente distinguible de los complejos procesos de formación del modo capitalista de producción y relación social. Cuando piensan la sociedad civil, se entrevé que los autores de El orden de El Capital se han negado previamente el derecho a precisarla: se presupone que no se trata de la polis griega, o de la koinomía politiké en general, pero no es posible saber por qué. Es transparente que no denuncian las mistificaciones legales de la sociedad política a la manera marxista tradicional, pero no se puede saber qué modelo de sociedad civil defienden. Parecería incluso que sólo existiera uno, el espacio civil liberal clásico, que debe ser «liberado» a su vez del modo capitalista de producción (ipor el comunismo!) Existen más alternativas: quizá se trate, marxianamente, de la

\footnotetext{
${ }^{21}$ Kervégan, J. F.: Hegel, Carl Schmitt. Lo politico: entre especulación y positividad, Madrid, Escolar y Mayo, 2007, p. 180 y siguientes. Cfr. Kervégan, J. F.: «Sociedad civil y derecho privado. Entre Hobbes y Hegel», en Res Publica. Revista de filosofía política, no 3, 1999, pp. 107-126.
} 
restitución de lo político a la sociedad civil (la ausencia de Estado como meta del proyecto emancipatorio comunista), pero entonces no podría pensarse como deseable la propiedad de la propia función (el presunto estatuto libre e independiente del funcionario, tal como los autores defienden); esto se debe a que, en última instancia, la determinación concreta de la función debe provenir ni más ni menos que del Estado. Algo parecido cabe decir del potencial marco jurídico-político republicano socialista que los autores defienden: los derechos asociados a la persona y al trabajo, al igual que los derechos asociados a la vida social o la juridificación de la propiedad privada, entre otros, son resortes que no se deducen en ningún caso del mero espacio civil, sino que exigen una intervención explícita de agencias de acción legislativa (bien el nivel más alto bien en el ámbito más reducido de las prácticas sociales compartidas). No hay forma pura del derecho que produzca norma republicana porque, entre otros motivos, la tradición republicana (socialista) no opera en el plano de las teorías ideales 22 . Pero, a su vez, parte importante de la tradición marxista ha venido negando esta sola posibilidad teórica al definir la sociedad civil, prolongando la tradición hegeliana, como el «conjunto de relaciones sociales que caen fuera del campo estatal» 23 . En conocidas palabras de Marx: «sólo la superstición política de hoy imagina que la vida social debe mantenerse unida a través del Estado, cuando en realidad es el Estado el que se mantiene unido por la vida civil» 24 . En todo caso, esta oscuridad en torno a la definición de sociedad civil, tanto en su vertiente metodológica de las ideas como en su sustento teórico, no sólo dificulta la lectura del libro, sino que afecta profundamente a sus fundamentos. Paso ahora a plantear otro problema relacionado.

(b) En segundo lugar, cabe preguntarse por el objeto de El orden de El Capital en lo que al ámbito de la sociedad civil se refiere. ¿Se trata de liberarla de restricciones capitalistas o de construir una sociedad política republicana? Locke pudo decir todavía sociedad civil o política. Nosotros ya no podemos. ¿O más bien se trata de vaciarla primero del modo de producción capitalista y de, ulteriormente, llenarla de republicanismo socialista? ¿Se puede defender el comunismo y al mismo tiempo no tener una idea precisa de los procesos de (re)construcción de la sociedad civil que semejante proyecto emancipatorio habría de emprender? Me parece que un proyecto republicano bien temperado, también preliminarmente bajo la forma de una lectura republicana de Marx, ha de escoger bien sus objetos. Si se trata de un

\footnotetext{
22 Cfr. Bertomeu, M. J. y Domènech, A.: op. cit., p. 65. Sigo a Domènech en el desarrollo que viene a continuación. Cfr. Domènech, A.: El eclipse de la fraternidad, Barcelona Crítica, 2004, p. 45 y siguientes, así como «Ética y economía de bienestar: una panorámica», en O. Guariglia (ed.), Cuestiones morales, Madrid, Trotta, 2007, p. 212-215.

${ }^{23}$ Giner, S.: op. cit., en E. Díaz y A. Ruiz Miguel (eds.), Filosofía Política, II. Teoría del Estado, op. cit., p. 123.

${ }^{24}$ Citado en Giner, S.: op. cit., en E. Díaz y A. Ruiz Miguel (eds.), Filosofía Política, II. Teoría del Estado, op. cit., p. 124.
} 
republicanismo normativo, no escogerá el derecho puro como garante de la multiplicidad inherente a las sociedades modernas, sino más bien las motivaciones (más plurales todavía) de los agentes. Si se apoya en la crítica de la economía política, entonces verá la sociedad civil como espacio de antagonismos e instituciones históricamente contingentes asociadas a la emergencia de la burguesía capitalista liberal, y no desde el punto de vista de un derecho apolítico puro que regiría las relaciones de sujetos apolíticos plurales (sean estos puros o impuros, more heideggeriano). Las sociedades no son para la tradición republicana agregados de corporaciones privadas (escuela, familia, iglesia, colegio profesional, empresa privada, etc.) Se trata más bien de «entramados institucionales en toda su jerarquía y dinámica causal» ${ }^{25}$ que, por definición, no se piensan pura sino históricamente, y que desde luego no se dejan pensar primero pura y luego históricamente, lo cual reproduciría, dicho sea de paso, la crítica de Luis Alegre y Carlos Fernández Liria a la tradición marxista-historicista. Tradición -en efecto, raquítica en honestidad filológica, efectivos teóricos y fuentes fidedignas- que fue sin embargo muy eficaz a través de los partidos comunistas y, por el lado liberal, enormemente influyente gracias al esfuerzo polémico contra el marxismo de algunos muy relevantes y honestos críticos à la Popper (si bien más atentos a la causa antiestalinista que a la palabra de Marx). Es bien sabido: tomando pie político en el presunto descubrimiento por Marx de las leyes de la historia y en la inexorabilidad del triunfo de un proletariado rampante, a éste sólo le quedaría esperar, muy pacientemente, eso sí, a la celebración de tan sonado logro.

A este respecto, John Rawls (un pensador de fuerte vena kantiana y por momentos muy republicana, dejando provisionalmente de lado el no menos fuerte sustrato liberal que posee su concepción de la libertad26) es un buen exponente del pathos plural de la teoría republicana. Dice Rawls en la conferencia VII de El liberalismo político que «la estructura básica de la sociedad es el primer objeto de la justicia» 27 , esto es, el espacio civil activo que se forma a través de las principales instituciones «hasta constituir un sistema único, así como el modo en que éstas [instituciones, EMZ] asignan derechos y deberes fundamentales y configuran la distribución de las ventajas surgidas de la cooperación social» 28 . Me parece la de Rawls una estrategia metodológicamente republicana, en tanto que considera que la familia, no menos que la propiedad o los Ministerios de Economía, forman parte de la estructura básica de la sociedad y constituyen, por tanto, su objeto. En consecuencia, una teoría republicana de la justicia debe pensar un conjunto de fondo de condiciones equita-

\footnotetext{
25 Bertomeu, M. J. y Domènech, A.: op. cit., p. 67.

26 Dicho sea de paso, no se hallará en Rawls a un socialdemócrata, como suele decirse y yo mismo he pensado y dicho en diversas ocasiones: mea culpa.

${ }^{27}$ Rawls, J.: El liberalismo político, traducción de A. Domènech, Barcelona, Crítica, 2004, p. 295.

28 Rawls, J.: El liberalismo político, op. cit., pp. 295-296.
} 
tivas que no pueda ser socavado aun cuando nadie actúe equitativamente en sus relaciones sociales singulares. Y no al revés, como creo defienden Carlos Fernández Liria y Luis Alegre: que las personas no irían naturalmente al mercado de no existir el modo de producción capitalista. Esta lectura -sea veraz o no- sólo puede deberse a que su objeto es, inadvertidamente, la psicología social del sujeto de derecho puro e indeterminado que defienden, correderas de pensamiento éstas más bien neoclásicas y no clásicas-republicanas. Se trata, ante todo, de una forma a-histórica de hacer filosofía política, puesto que apela a los rudimentos psicológicos de los sujetos, a su equipamiento moral de serie, a la razón en singular, y sólo posteriormente a su expresión social e históricamente contingente en un conjunto de prácticas entrecruzadas [creo leer en El orden de El Capital que «libremente escogidas» una vez consumada la retirada definitiva del capital]. En definitiva, se trata de una teoría que se presenta idealmente vacía por mor de la demostración de la incompatibilidad de capitalismo y derecho [imposible maridaje incluso con el liberalismo político más potente que -aquí sí tienen, me parece, toda la razón-entroncaría kantianamente con los principios a priori de libertad, igualdad e independencia], pero que, en el desempeño de esa muy digna tarea, ya no puede ser tomada por republicana (socialista).

2.3. El último punto al que quiero referirme es la noción de libertad tal como opera en el texto de Luis Alegre y Carlos Fernández Liria, que si bien pudiera ser tendencialmente compatible con la libertad marxianamente entendida, no es republicana. Me explico: los autores se encomiendan -entiendo que con el afán polémico y retórico de mostrar el absurdo que supone que el capitalismo sea inconsistente incluso con sus formas más avanzadas de legitimación, esto es, el esquema trinitario «libertad económica, libertad política y bienestar social para la mayoría»- a los principios de la libertad civil en Kant, más concretamente a su expresión en el ensayo «Sobre el tópico» de 1793: «nadie me puede obligar a ser feliz a su modo (tal como se imagine él el bienestar de otros hombres), sino que es lícito a cada uno buscar su felicidad por el camino que mejor le parezca, siempre y cuando no cause perjuicio a la libertad de los demás para pretender un fin semejante» (citado en p. 20). Esta definición negativa de libertad (que no contiene sólo un momento liberal, sino también republicano, siempre con primacía evidente del primero) es completada con la defensa del principio de propiedad y del derecho a la existencia digna, bien (1) por la vía clásica (que en efecto no es la única) por la cual sólo aquél que sea propietario de un objeto exterior podrá participar activamente en la vida civil sin temer en cada momento por su existencia, bien (2) por otras vías aún sin explorar [entre las cuales se destaca la propiedad de la función y se descarta, a mi modo de ver correctamente, la ficción de la propiedad del propio pellejo o la fuerza de trabajo como sustento de un mercado libre e igual al que concurrirían propietarios de 
mercancías potencialmente equivalentes: léase un kilogramo de oro por dos años de jornadas laborales de 14 horas hábiles diarias de lunes a sábado]. Estoy de acuerdo con esta línea de argumentación, tanto desde el punto de vista polémico como desde una consideración positiva de la definición kantiana. Eso sí, no puedo menos que sugerir que se establezca claramente que (1) dicha noción opera en un nivel de abstracción impropio de la tradición republicana clásica [el derecho puro que los autores defienden como forma privilegiada de fundamentación de la libertad civil more kantiano], y (2) que no se trata de la idea republicana (socialista) de libertad. Ésta tendría más bien las siguientes determinaciones ${ }^{29}$ :

(1) Se es republicanamente libre si no se depende de otro particular para vivir -esto es, tal como Carlos Fernández Liria, Luis Alegre y multitud de tradiciones filosóficas incompatibles entre sí defienden- no se depende del arbitrio de otro de cara a obtener o perseguir un proyecto de vida concreto o, más sencillamente, sobrevivir en el espacio social bajo condiciones de existencia digna.

(2) Se es republicanamente libre si nadie puede interferir arbitrariamente en la existencia social de otro. Esto es, en su propiedad, salario, condiciones laborales y de reproducción social y familiar $\mathrm{y}$, en general, los medios de su existencia social.

(3) Se es republicanamente libre si existen en el espacio social instituciones republicanas (o, más directamente, repúblicas democráticas de pleno derecho institucionalmente provistas) que pueden intervenir lícitamente en la existencia social de unos y otros por igual, estando todos facultados para gobernar y ser gobernados. Es el caso, por ejemplo, de una acumulación (i)lícita de propiedad privada tan grande que amenace la gobernabilidad de un país porque de facto puede provocar a las instituciones para sustituirlas eventualmente de iure y así violentar los principios 1 y 2 o fomentar las condiciones apropiadas para su violabilidad.

(4) No se es republicanamente libre si cualquier intervención de unos u otros sobre un particular o varios particulares que les haga perder su autonomía social es declarada lícita por las instituciones. Por ejemplo, la expropiación de una vivienda que había llegado a ser propiedad de un particular por la vía de un préstamo hipotecario ambiguo o directamente injusto que, por un motivo u otro, fuera aceptado explícita o implícitamente por ese particular sin conocimiento efectivo de sus posibles consecuencias. Existen ya precedentes judiciales de anulación de cargas hipotecarias, en este sentido concreto, en el ámbito europeo.

${ }^{29}$ Cfr. Bertomeu, M. J. y Domènech, A.: op. cit., p. 68 y siguientes. Sigo a ambos de cara a desarrollar la idea de libertad republicana. 
(5) No se es republicanamente libre, enlazando con el tercer principio, si un particular puede disputar a las instituciones la determinación del bien público (sea cual sea éste en cada momento o lugar históricamente determinado, sometido democráticamente a escrutinio público periódico) y las instituciones no están legitimadas o facultadas para intervenir.

(6) Se es republicanamente libre si, dentro de la vida social, se tiene un conjunto de derechos cívicos constitutivos inalienables y no instrumentales tanto en el sentido de indisponibles (por ejemplo, la modificación arbitraria de las condiciones laborales en tiempos social e históricamente determinados de recesión económica) como por el lado de su condición de no susceptibles de ser intercambiados por dinero o privilegios del tipo que sea, a riesgo de perder la condición de la ciudadanía.

En este sentido, parece obvio que en la vida social en el capitalismo realmente existente no se dan estas condiciones de ciudadanía, y que este hecho afecta del todo a la condición de la persona, bien como hombre bien como ciudadano. Pero no me parece menos importante destacar que resulta prácticamente imposible conjugar la definición kantiana de libertad ya mencionada, se haga operar positiva o polémicamente, con la concepción clásica republicana. Estoy convencido de que Carlos Fernández Liria y Luis Alegre están de acuerdo con los seis postulados anteriores, pero no veo cómo pueden considerar, metodológica y sustantivamente, que puedan ser deducidos de la forma pura del derecho. Al menos cuatro de los seis exigen la defensa activa de una concepción específica del bien común que, si bien no ha de ser idealmente incompatible con otras concepciones del bien y la vida buena, de hecho lo es. Es aquí donde la tradición liberal republicana, en el mejor sentido de la filosofía política clásica, ha operado con éxito: el mismo Rawls ha querido pensar instituciones vertebradoras de la estructura básica de la sociedad que hagan posible tener una idea del bien común [y por descontado, una raza, una religión, una ideología, un conjunto de preferencias éticas, estéticas, políticas y psicosociales, completamente inconmensurables e indisponibles] y, al mismo tiempo, defender un orden institucional sustantiva y procedimentalmente justo capaz de soportar un número ingente de virtudes y defectos (incompatibles entre sí) que no puedan ser homogeneizados en nombre de la democracia formal, el socialismo realmente existente (en su vieja forma soviética o cualesquiera otras por venir) o el neoliberalismo. Me explico: se trataría de articular, más allá del liberalismo pero contando con él, articulaciones alternativas a la libertad negativa. O lo que es lo mismo: emanciparse filosóficamente de la muy restrictiva distinción berliniana entre la libertad negativa [patrimonio, se entiende aquí, de la tradición liberal, aunque no exclusivamente] y la positiva [que debería, por su parte, tomarse muy en serio el pluralismo de la sociedad y acordar los principios cívicos de la estructura básica de la sociedad 
en el ámbito político -no metafísico- de la razón pública30]. Es aquí donde la reactivación de Marx y la tradición republicana, no sólo en su vertiente socialista, puede ser de ayuda. Igualmente, me parece relevante, pese a lo mucho que en apariencia complica el diagrama, el pensamiento político vinculado al Institut für Sozialforschung en el exilio [Neumann y la tradición del derecho laboral alemán de entreguerras, también ciertos Benjamin y Adorno, no tanto por la vía política republicana, que no transitan, como por sus análisis de la sociedad civil y su fértil actividad como hermeneutas materiales de las sociedades capitalistas avanzadas].

Concretando más: me parece francamente valiosa la filosofía jeffersoniana de la práctica, para la cual la democracia es tanto fin como medio, «ahí donde cada hombre tome parte en la dirección de su república de distrito [...] no solamente un día de elecciones al año, sino cada día» ${ }^{31}$. Jefferson piensa en un fin concreto [la democracia republicana] que, por su naturaleza revolucionaria, exige un medio igualmente transparente y activo [a saber, ella misma]. Por eso puede plantear la continuidad entre rebelión y constitución: porque ésta, si es esencialmente republicana y democrática, no está concebida para atrofiarse: el núcleo duro de la educación republicana consiste en la producción activa de tejido social democrático, la creación continua de experiencias (democráticas), y no la sujeción a criterios instrumentales para la obtención de fines políticos particulares o ventajas socioeconómicas comparativas frente a otras comunidades. La transición continua defendida por Jefferson tiene, en este sentido, la virtualidad de modular la importancia de la relación entre medios y fines, entre el principio del proceso de transformación y la consumación del mismo [históricamente uno de los más importantes quebraderos de cabeza de todo proyecto político emancipatorio].

Pienso también en la obra de Antonio Gramsci: su atenta mirada a la sociedad civil como esfera privilegiada de lo político es de suyo republicana. En términos muy generales, Gramsci trata de negar explícitamente la distinción -como ya hiciera Locke- entre sociedad civil y sociedad política. Además, su lectura madura de Marx es, en mi opinión, más productiva y realista que la de Althusser. Marx aparece ahora como auténtico campeón de la filosofía inmanente: «ese pensamiento no sitúa nunca como factor máximo de la historia los hechos económicos en bruto [...] sino siempre el hombre, la sociedad de los hombres, de los hombres que reúnen, se comprenden, desarrollan a través de esos contactos (cultura) un voluntad social [...]

30 Partiendo del pluscuaminterpretado artículo de J. Rawls «Justice as Fairness: Political not Metaphisical» (1985), A. de Francisco ha desarrollado una argumentación similar en «Las tres lógicas de la ciudadanía», en Claves de razón práctica, $\mathrm{n}^{\circ} \mathrm{XX}, \mathrm{pp}$. 2-9. El texto de Rawls puede encontrarse en una buena versión española en C. Gómez (ed.), Doce textos fundamentales de la Ética del siglo XX, Madrid, Alianza, 2003, p. 187 y siguientes. Agradezco a Carlos Fernández Liria la referencia al artículo de Andrés de Francisco.

31 Jefferson, Th.: La declaración de independencia, edición de M. Hardt, Madrid, Akal, 2009, p. 129. Se trata de una carta de Jefferson a Joseph Cabell con fecha del 2 de febrero de 1816. 
y entienden los hechos económicos, los juzgan y los adaptan a su voluntad hasta que ésta se convierte en motor de la economía» 32 .

En definitiva, todavía hoy permanece vigente el viejo dilema decimonónico: las leyes dictan por igual a ricos y pobres que no se permite dormir debajo de los puentes. Pero es bien sabido que los ricos no duermen debajo de los puentes porque no tienen ninguna necesidad de hacerlo. Los pobres, al menos eventualmente, pueden tener que hacerlo. Si el trabajo de Carlos Fernández Liria y Luis Alegre aspira a fundamentar filosóficamente un proyecto emancipatorio deberá, en mi opinión, habérselas con esta problemática, y no tanto con el thema probandum de la incompatibilidad de los ideales de libertad igualdad y propiedad con el modo capitalista de producción realmente existente (que no es el mismo, valga la obviedad, que Marx pudo analizar en vida). Una lectura republicana de Marx constituye un reto filosófico de enorme entidad, demasiada como para confiar (en exclusiva) en la tradición marxista [tampoco en su rama teoreticista à la Althusser, cuyo influjo sobre El orden de El Capital se me antoja excesivo] o la filosofía política de Kant33. No niego, claro está, el interés del esfuerzo de Carlos Fernández Liria y Luis Alegre, pero sí considero, en resumidas cuentas, que su libro adolece de algunos defectos (dicho queda, de orden metodológico y sustantivo) que (1) afectan a su explícita tarea ulterior [la de analizar y desconfigurar el Orden del capital, y no sólo el orden de El Capital, para así ponerse en disposición de ofrecer alternativas razonables no ya desde un punto de vista republicano, sino productivamente republicanas ${ }^{34}$ ] y (2) hacen operar una desconexión profunda entre los momentos marxiano [«salvar a Marx del marxismo») y republicano de su libro, discontinuidad que arroja dudas importantes sobre el proyecto.

32 Gramsci, A.: citado en M. Sacristán, El orden y el tiempo, Madrid, Trotta, 1998, p. 124.

33 Existen asimismo precedentes de lecturas que buscan en Kant, sin reprimir su vertiente liberal, principios activos asociados a momentos republicanos. Pienso en un libro de Domenico Losurdo muy recientemente traducido a nuestra lengua: Autocensura y compromiso en el pensamiento político de Kant, Madrid, Escolar y Mayo, 2011. Allí trata su autor de establecer una lectura republicana de Kant que asocia la defensa de la razón legisladora con la defensa del proyecto revolucionario francés en su vertiente tanto jacobina como, en cierto sentido, post-termidoriana, con calas muy interesantes en el ensayo «Sobre el tópico» (1793) o El conflicto de las facultades (1798). Losurdo apela, en una línea próxima a la de Carlos Fernández Liria y Luis Alegre, al edificio racional asociado a las leyes de la libertad y los principios a priori [Freiheit, Gleichheit, Selbstständigkeit], pero vinculándolos ineludiblemente los sucesos históricos del periodo 1789-1793 y a los debates propios de la época (Forster, Mehring, Cotta, Hölderlin, Fichte, Wieland, Sieyès, etc.) Allí, sin embargo, el edificio del derecho es historizado con considerable productividad.

34 No estoy en condiciones de avanzar más en esta lectura parcial del libro de Carlos Fernández Liria y Luis Alegre, pero sí dejo caer, por si fuera de interés, dos posibles líneas de trabajo importantes: la teoría de la sociedad civil de Hegel tal como consta en la Filosofía del derecho de 1820/1821 y la filosofía política moderna y contemporánea de cuño anglosajón (el segundo Rawls, muy particularmente, aunque también algunos modernos teóricos de la Revolución americana: Thomas Jefferson y Thomas Paine). 
Eduardo Maura Zorita

Departamento de Filosofía IV

Facultad de Filosofía

Universidad Complutense de Madrid

emauraz81@hotmail.com 